\title{
Spectroscopic Studies on Dual Role of Natural Flavonoids in Detoxification of Lead Poisoning: Bench-to-Bedside Preclinical Trial
}

\author{
Aniruddha Adhikari, ${ }^{\dagger, \perp}$ Soumendra Darbar, ${ }^{\dagger} \perp$ Tanima Chatterjee, ${ }^{\S}$ Monojit Das, ${ }^{\|}$Nabarun Polley, ${ }^{\dagger}$ \\ Maitree Bhattacharyya, ${ }^{\S}$ Siddhartha Bhattacharya, $"$ Debasish Pal, ${ }^{\|}$and Samir Kumar Pal*,, , ${ }_{\odot}$ \\ ${ }^{\dagger}$ Department of Chemical, Biological and Macromolecular Sciences, S. N. Bose National Centre for Basic Sciences, Block JD, Sector \\ III, Salt Lake, Kolkata 700 106, India \\ ${ }^{\ddagger}$ Research \& Development Division, Dey’s Medical Stores (Mfg.) Ltd, 62, Bondel Road, Ballygunge, Kolkata 700019, India \\ ${ }^{\S}$ Department of Biochemistry, University of Calcutta, 35, Ballygunge Circular Road, Kolkata 700019, India \\ "Department of Zoology, Uluberia College, University of Calcutta, Uluberia, Howrah 711315, India
}

\author{
Supporting Information
}

\begin{abstract}
Ubiquitousness in the target organs and associated oxidative stress are the most common manifestations of heavy-metal poisoning in living bodies. While chelation of toxic heavy metals is important as therapeutic strategy, scavenging of increased reactive oxygen species, reactive nitrogen species and free radicals are equally important. Here, we have studied the lead $\mathrm{Pb})$ chelating efficacy of a model flavonoid morin using steady-state and picosecond-resolved optical spectroscopy. The efficacy of morin in presence of other flavonoid (naringin) and polyphenol (ellagic acid) leading to synergistic combination has also been confirmed from the spectroscopic studies. Our studies further reveal that antioxidant activity (2,2-diphenyl-1-picrylhydrazyl assay) of the $\mathrm{Pb}$-morin complex is sustainable compared to that of $\mathrm{Pb}$-free morin. The metal-morin chelate is also found to be significantly soluble compared to that of morin in aqueous media. Heavy-metal chelation and sustainable antioxidant activity of the soluble chelate complex are found to accelerate the $\mathrm{Pb}$-detoxification in the chemical bench (in vitro). Considering the synergistic effect of flavonoids in $\mathrm{Pb}$ detoxification and their omnipresence in medicinal plants, we have prepared a mixture (SKP17LIV01) of flavonoids and polyphenols of plant origin. The mixture has been characterized using high-resolution liquid chromatography assisted mass spectrometry. The mixture (SKP17LIV01) containing 34 flavonoids and 76 other polyphenols have been used to investigate the $\mathrm{Pb}$ detoxification in mouse model. The biochemical and histopathological studies on the mouse model confirm the dual action in preclinical studies.
\end{abstract}

\section{INTRODUCTION}

Lead $(\mathrm{Pb})$, one of the most widely used metals in the industry and simultaneously a versatile, subtle, and persistent poison present in Earth's crust, can induce a wide array of physiological, biochemical, and behavioral dysfunctions affecting almost every organ system (central and peripheral nervous, hematopoietic, respiratory, cardiovascular, renal, hepatic and reproductive system) cumulating in death. ${ }^{1-4}$ Although $\mathrm{Pb}$ toxicity has been documented as early as $2000 \mathrm{BC}$ and found to be preventable, victims of such toxicity in human civilization are evident in recent times. ${ }^{5}$ Even in 2015, 494550 deaths occurred due to $\mathrm{Pb}$ exposure, which is $0.6 \%$ of the global burden of diseases and 9.3 million disability-adjusted life years. $^{4,6,7}$ Of particular concern is the role of $\mathrm{Pb}$ exposure in the development of intellectual disability in children. ${ }^{7}$ Though there is wide recognition of this problem and many countries have acted to stop its use, exposure to $\mathrm{Pb}$, particularly in childhood, remains a key concern for health care providers and public health officials worldwide. Though $\mathrm{Pb}$ itself is a nonredox metal and does not possess any prooxidant catalytic activity, it rather converts to some indirect mechanisms [e.g., auto-oxidation of hemoglobin $(\mathrm{Hb})$, accumulation, and subsequent auto-oxidation of $\delta$-aminolevulinic acid induced by $\mathrm{Pb}$ ] for imparting pathogenesis via oxidative disturbances. ${ }^{4,8-10}$ Thus, controlling the free-radical-induced intracellular damage is equally important in combating $\mathrm{Pb}$ poisoning alongside the removal of the same from organs. On the other hand, the currently approved treatment for $\mathrm{Pb}$ toxicity (use of chelating agents such as 2,3-dimercaptosuccinic acid and $\mathrm{CaNa}_{2}$ EDTA) can neither be used at a therapeutically adequate dose for a prolonged period of time owing to a number of shortcomings and inherent toxicity (e.g., nephrotoxicity, cardiotoxicity, zinc dieresis, nausea, fever, and breathing trouble) nor reduce the significant oxidative stress

Received: October 27, 2018

Accepted: November 8, 2018

Published: November 27, 2018 
generated due to cellular $\mathrm{Pb}$ exposure. ${ }^{3,11}$ Therefore, considering the indispensable necessity of an alternative therapeutic approach, an exogenously supplied chelator with sustainable antioxidant activity even after complexation with $\mathrm{Pb}$ can be an ideal therapeutic detoxification strategy.

Flavonoids, a class of natural polyphenols with a benzo- $\gamma$ pyrone structure ubiquitously present in plants, are widely known for their antioxidant activity. ${ }^{12-14}$ Since their discovery in 1936, several studies have determined the flavonoid antioxidant activity, many of which have used pure compounds, calculated individual antioxidation power, and performed structure-activity relationship studies. ${ }^{14-16}$ In other studies, the antioxidation power of a given food or plant sample has been characterized in depth and, in some cases, the correlation between flavonoid composition and antioxidation power has been examined. ${ }^{17-19}$ The other most studied property of flavonoids is the metal ion chelation ability. Several studies have reported interactions between flavonoids and metal ions leading to chelate formation, which are only slightly active in the promotion of free-radical reactions. ${ }^{13,20-22}$ Although several studies have shown that plants use this chelation property for the detoxification of heavy metals, ${ }^{23-25}$ in-depth study on the interaction of heavy metals with flavonoids is sparse in contemporary literature. Some of the recent studies focus on the antioxidation properties of flavonoid-transition-metal complex (e.g., $\mathrm{Fe}^{3+}, \mathrm{Cr}^{3+}, \mathrm{Cu}^{2+}$, and $\left.\mathrm{Al}^{3+}\right) \cdot{ }^{26-31}$ However, to the best of our knowledge, no study has addressed the sustainable antioxidation activity imparted due to heavy-metal chelation to flavonoid alone or in mixture with other polyphenols and is one of the motives of the present study.

Here, we have studied a model heavy-metal $(\mathrm{Pb})$ chelating efficacy of a model flavonoid (morin) using steady-state and picosecond-resolved optical spectroscopy. The efficacy of morin in the presence of other flavonoid (naringin) and polyphenol (ellagic acid, EA) leading to synergistic combination has also been confirmed from the spectroscopic studies. This is particularly important because previous observations suggest that polyphenolic mixtures show fewer side effects than the pure compounds due to interactions among themselves. $^{32,33}$ Our studies reveal that the antioxidant activity [2,2-diphenyl-1-picrylhydrazyl (DPPH) assay] of the $\mathrm{Pb}-$ morin complex is sustainable compared to that of $\mathrm{Pb}$-free morin. We have also found that the solubility of the $\mathrm{Pb}-$ morin complex increases significantly compared to that of morin in an aqueous environment. Heavy-metal chelation and sustainable antioxidant activity of the chelate complex are found to accelerate the $\mathrm{Pb}$ detoxification in the chemical bench (in vitro). Considering the synergistic effect of flavonoids in $\mathrm{Pb}$ detoxification and their omnipresence in medicinal plants, we have prepared a mixture (SKP17LIV01) of flavonoids containing 34 flavonoids and 76 other polyphenols and investigated the $\mathrm{Pb}$ detoxification in mouse model. The biochemical and histopathological studies confirm the dual action in preclinical studies. Our studies on biodistribution of $\mathrm{Pb}$ in various target organs of the intoxicated mice using inductively coupled plasma-assisted atomic emission spectroscopy (ICP-AES) confirm that SKP17LIV01 efficiently facilitates excretion of $\mathrm{Pb}$ from mice body after heavy-metal chelation and sustainable reactive oxygen species (ROS) scavenging in vivo.

\section{MATERIALS AND METHODS}

Materials. Morin, EA, naringin, quercetin, lead nitrate $\left(\mathrm{Pb}\left(\mathrm{NO}_{3}\right)_{2}\right)$, sodium chloride $(\mathrm{NaCl})$, sodium hydroxide $(\mathrm{NaOH})$, and DPPH were purchased from Sigma (St. Louis, MO, USA). All solvents were obtained from Merck (NJ, USA) unless otherwise stated. All reagents were of analytical grade and used without further purification. Nanopure water (resistivity $\geq 18 \mathrm{M} \Omega \mathrm{cm}$ ) from Milli-Q system (Millipore $\mathrm{GmbH}$, Germany) was used whenever required. In order to prepare a mixture of flavonoids and polyphenols, we have used a well-characterized (by using ultra-high-performance liquid chromatography mass spectrometry; UHPLC-MS) extract from eight medicinal plants (Table S1). We call the mixture to be SKP17LIV01. The detailed characteristics and systems pharmacology of the extract will be published elsewhere.

Fingerprint Analysis Using UHPLC-MS. For complete chemical characterization of SKP17LIV01, we used fingerprint analysis by ultra-high-resolution LC-MS. Mass spectra were recorded by electrospray ionization in both negative and positive modes using an Agilent 1290 Infinity UHPLC System (MS Q-TOF, model G6550A, Agilent Technologies, CA, USA) equipped with a C-18 stainless steel column $(30 \mathrm{~cm} \times$ $0.46 \mathrm{~cm})$. The capillary voltage was kept at $80 \mathrm{~V}$, and the air (nebulizing gas) pressure was 35 psi. Full scan data acquisition was performed by scanning from $\mathrm{m} / z 50$ to 1000 with isolation width $\approx 4.0 \mathrm{amu}$. The oven temperature was set to $40{ }^{\circ} \mathrm{C}$, and mobile phase A consisted of $100 \%$ water, whereas mobile phase B consisted of a mixture of $90 \%$ acetonitrile, $10 \%$ water, and $0.1 \%$ formic acid. Sample $(0.02 \mathrm{~mL})$ was injected. A flow rate of $0.2 \mathrm{~mL} / \mathrm{min}$ was used. An elution gradient ranging from $5 \%$ B to $95 \%$ B from 0 to $20 \mathrm{~min}$ was used. Identification of major compounds was accomplished by analyzing the molecular ion peak and base peak using an Agilent MassHunter Workstation (Agilent Technologies CA, USA).

UV-Vis and Fluorescence Spectroscopy. Optical absorbance spectra were recorded on a double-beam spectrophotometer (model UV-2600, Shimadzu, Japan) in the $200-800 \mathrm{~nm}$ range. Fluorescence spectra were obtained with a fluorescence spectrophotometer (LifeSpec-ps, Edinburgh Instruments, UK) equipped with a microchannel platephotomultiplier tube (MCP-PMT, Hamamatsu, Japan). The excitation wavelength was set at $375 \mathrm{~nm}$. Fluorescence spectra were corrected for variations with wavelength in source intensity, photomultiplier response, and monochromator throughput.

Solutions and Experimental Method. Stock solutions of morin, naringin, and EA were prepared in $0.01 \mathrm{~N} \mathrm{NaOH}$. They were further diluted using water as a solvent. $\mathrm{NaCl}$ was used to keep the ionic strength constant $(0.1 \mathrm{M})$. Incremental volumes of $\mathrm{Pb}\left(\mathrm{NO}_{3}\right)_{2}$ stock solution $(0.15 \mathrm{M})$ were added to the polyphenol reaction mixture in order to vary the molar ratio, and the $\mathrm{pH}$ was maintained constant $(\mathrm{pH}=7.4)$ by small additions of $\mathrm{NaOH}$. A syringe pump (Pump 11 Pico Plus Elite, Harvard Apparatus, MA, USA) was used to circulate the solution from the titration beaker to the experiment cell. UVvis absorbance and fluorescence spectra were recorded for each molar ratio and used for further calculations. All measurements were performed in a $1 \mathrm{~cm}$ quartz cuvette, hermetically closed, and thermostatized at $298.0 \pm 1.5 \mathrm{~K}$.

Time-Correlated Single-Photon Counting Measurement. PL transients of the solutions were measured and fitted using a commercially available picosecond diode laser-pumped 
time-resolved fluorescence spectrophotometer (LifeSpec-ps, Edinburgh Instruments, UK) [excitation wavelength $375 \mathrm{~nm}$, $80 \mathrm{ps}$ instrument response function (IRF)] with a temperature controller attachment (Julabo, model F32). Time-correlated single-photon counting (TCSPC) technique was used to capture all transients. Photoluminescence was detected from the samples using a MCP-PMT (Hamamatsu, Japan) after dispersion through a grating monochromator (polarizer was set at $55^{\circ}$ ). The observed fluorescence transients are fitted by using a nonlinear least-square fitting procedure to a function

$$
\varphi(t)=\int_{0}^{t} E\left(t^{\prime}\right) R\left(t-t^{\prime}\right) \mathrm{d} t^{\prime}
$$

comprising convolution of IRF $(E(t))$ with a sum of exponentials

$$
\rho(t)=X+\sum_{i=1}^{n} Y_{i} \mathrm{e}^{-t / \tau_{i}}
$$

with pre-exponential factors $\left(Y_{i}\right)$, characteristic lifetimes $\left(\tau_{i}\right)$, and a background (X). Relative percentage in a multiexponential decay is finally expressed as

$$
c_{n}=\frac{Y_{n}}{\sum_{i=1}^{N} Y_{i}} \times 100
$$

The quality of the curve fitting is evaluated by reduced chisquared and residual data.

DPPH Assay. The free-radical scavenging activity of the samples of interest was determined using the DPPH method. Sample (0.5 mL, in varied concentration) was added to $3.0 \mathrm{~mL}$ of freshly prepared ethanolic DPPH solution $(0.1 \mathrm{mM})$. The change in absorbance was monitored at $535 \mathrm{~nm}$ for $60 \mathrm{~min}$. $\mathrm{EC}_{50}$ values were measured from the percentage inhibition at different concentrations.

$$
\text { Percentage inhibition }=\frac{A b s_{\text {control }}-\mathrm{Abs}_{\text {test }}}{A b s_{\text {control }}} \times 100 \%
$$

$\mathrm{EC}_{50}$ is the concentration value which scavenged $50 \%$ of the DPPH radicals. Trolox was used as the reference compounds.

For $\mathrm{DPPH}$ assay, synthesis of $\mathrm{Pb}(\mathrm{II})$-morin complex was done by the addition of solid $\mathrm{Pb}\left(\mathrm{NO}_{3}\right)_{2} \quad(0.1 \mathrm{M}$ final concentration) in ethanolic solution of morin $(0.01 \mathrm{M})$. The mixture was stirred for $1.5 \mathrm{~h}$. Then, it was filtered and subsequently evaporated on a rotary evaporator. The resulting product was washed with 1:1 t-butanol/chloroform to remove unreacted morin. An olive green product $\mathrm{Pb}(\mathrm{II})$-morin complex was then obtained, which was used for further studies.

Animal Model and Treatment. Six-week-old healthy Swiss albino mice weighing $25.1 \pm 2.0 \mathrm{~g}$, maintained in polypropylene cages under $12 \mathrm{~h} \mathrm{light/dark}$ cycle in a temperature $\left(25.0 \pm 1.5{ }^{\circ} \mathrm{C}\right)$ - and humidity $(50.0 \pm 5 \%)$ controlled room with food (Hindustan Lever, New Delhi, India) and water ad libitum, were randomly divided into four groups $(N=10$ /group $)$ after 2 weeks of acclimatization. Group I served as control and received physiological saline $(0.9 \%$ $\mathrm{NaCl}$ ) by oral gavage during the whole course of experiment. Groups II-IV intraperitoneally received an aqueous solution of $\mathrm{Pb}\left(\mathrm{NO}_{3}\right)_{2}[50 \mathrm{mg} / \mathrm{kg}$ body weight $(\mathrm{BW})]$ in every alternative day for 4 weeks for the induction of oxidative stress and associated liver damage. Then, group II was left untreated and served as a negative control. After induction, groups III and IV daily received (orally) SKP17LIV01 $(3.5 \mathrm{~mL} / \mathrm{kg} \mathrm{BW})$ and silymarin $(100 \mathrm{mg} / \mathrm{kg} \mathrm{BW})$, respectively. All animal experiments were performed according to the guidelines recommended by the Committee for the Purpose of Control and Supervision of Experiments on Animals (CPCSEA), New Delhi, India, and approved by the Institutional Animal Ethics Committee (approval no.-JU-Dey's/IAEC/09/14, dated 31.01.2014).

Blood Collection and Serum Isolation. At the end of requisite fasting period, blood was collected from each mouse by retro-orbital venous puncture and kept in microcentrifuge tubes with and without ethylenediaminetetraacetic acid $(2.0 \%)$. The tubes were placed in slanting position at room temperature (RT) for $2 \mathrm{~h}$. Then, they were centrifuged at $3500 \mathrm{~g}$ for $10 \mathrm{~min}$. Serum was separated and used for further analyses.

Assessment of Hematological and Liver Function Parameters. Biochemical parameters such as serum enzymes, aspartate aminotransferase (AST), alanine aminotransferase (ALT), serum alkaline phosphatase (ALP), gamma-glutamyl transferase (GGT), and total and direct bilirubin along with total protein (TP) were assayed using assay kits (Span Diagnostic, Surat, India) following the protocol prescribed by manufacturers. The European standardized method was used to determine the blood delta-aminolevulinic acid dehydratase (ALAD) activity. ${ }^{34}$ For hematological studies, the blood was collected in heparinized tubes. Hematological parameters were obtained by an automated cell counter (Medonic CA 620, Boule Diagnostics, Sweden). Parameters studied were $\mathrm{Hb}$, total red blood cell, reticulocyte, hematocrit, mean corpuscular volume, mean corpuscular $\mathrm{Hb}$, mean corpuscular $\mathrm{Hb}$ concentration, platelets, total white blood cell, and differential count.

In Vivo Distribution of $\mathrm{Pb}$ in Blood and Liver. The $\mathrm{Pb}$ (II) contents in the liver and blood were estimated using ICP-AES (ARCOS, SPECTRO Analytical Instruments GmbH, Germany). The samples were prepared using the open acid digestion method. In brief, dried tissues were dissolved in $\mathrm{HNO}_{3}(15 \mathrm{~mL}), \mathrm{H}_{2} \mathrm{SO}_{4}(10 \mathrm{~mL})$, and $\mathrm{H}_{2} \mathrm{O}_{2}(5 \mathrm{~mL})$, heated at $120{ }^{\circ} \mathrm{C}$ until only a residue remained, and then diluted with deionized water to $10 \mathrm{~mL}$.

Histopathology. For microscopic evaluation, a conventional technique of paraffin wax sectioning and differential staining was used. Liver tissues were excised, fixed in $10 \%$ neutral buffered formalin saline for $72 \mathrm{~h}$, dehydrated in graduated ethanol (50-100\%), cleared in xylene, and embedded in paraffin. Sections (4-5 $\mu \mathrm{m}$ thick) were cut using microtome, stained with hematoxylin and eosin (H\&E), and examined under an Olympus BX51 fluorescence microscope (Olympus Optical, Tokyo, Japan). In this staining process, hematoxylin gives deep blue-purple color to nucleic acid, whereas eosin provides pink color to the proteins. ${ }^{35}$

Tissue Homogenate Preparation. Tissues from the four groups of animals were collected, minced, and lysed in radio immunoprecipitation assay buffer (Sigma, USA) ( $5 \mathrm{mg}$ tissue in $0.5 \mathrm{~mL}$ buffer) for $30 \mathrm{~min}$. After centrifugation at $12000 \mathrm{~g}$ for $15 \mathrm{~min}$ at $4{ }^{\circ} \mathrm{C}$, supernatants were collected and stored in aliquots at $-80{ }^{\circ} \mathrm{C}$ for further use. Protein concentration of the aliquots was determined according to Bradford method.

Antioxidant Enzyme Activity and Lipid Peroxidation. The activity of superoxide dismutase (SOD) and catalase (CAT) was measured following reported methods. ${ }^{36,37}$ Reduced glutathione (GSH) was determined using Ellman's method. ${ }^{38}$ For activity measurement of glutathione peroxidase 

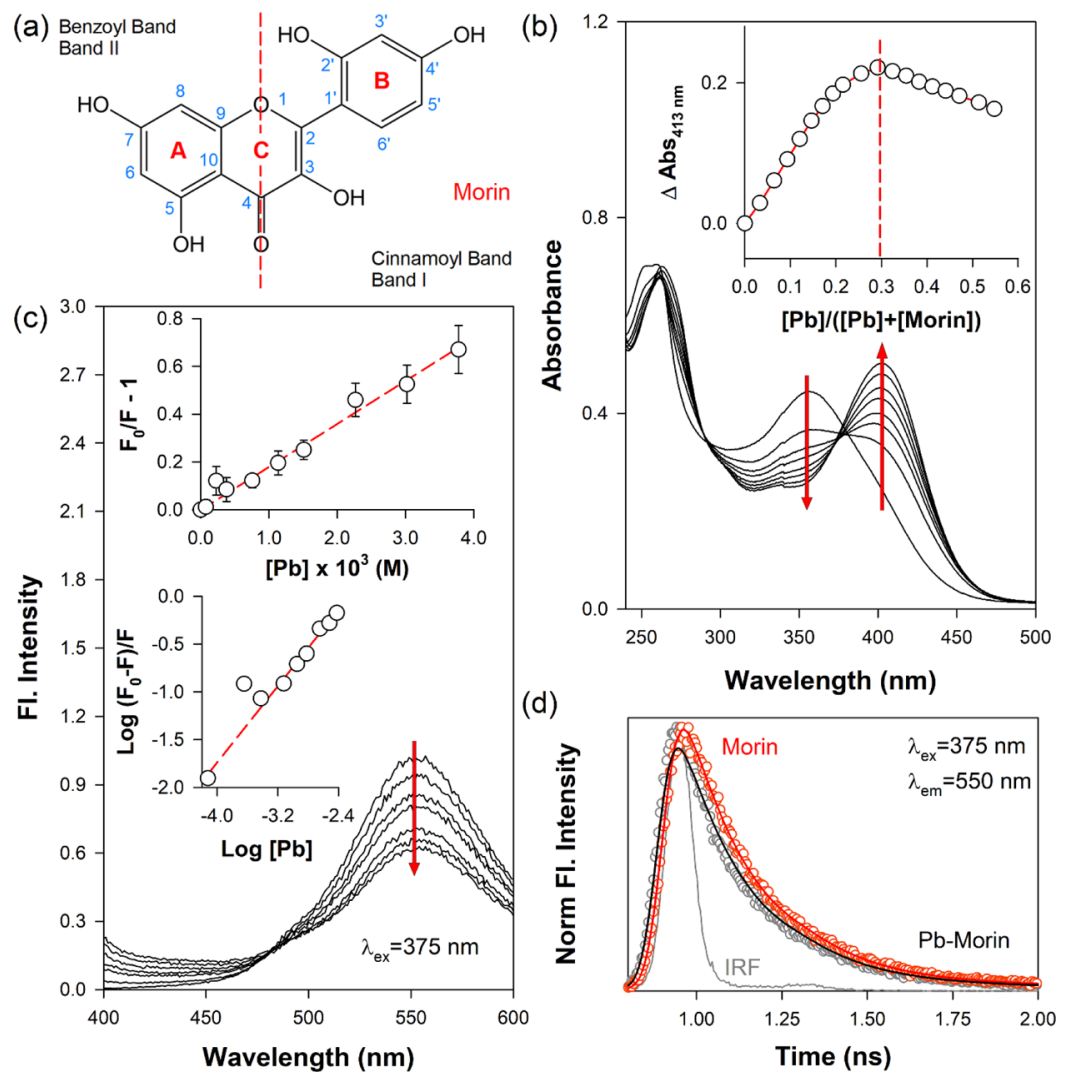

Figure 1. Interaction of $\mathrm{Pb}(\mathrm{II})$ with morin, a flavonol. (a) Chemical structure, numbering system, and UV-vis absorption bands of morin. (b) Absorption spectra of $4.09 \times 10^{-5} \mathrm{M}$ morin in the presence of varying concentrations $\left(0.15 \times 10^{-5}\right.$ to $\left.4.14 \times 10^{-4} \mathrm{M}\right)$ of $\mathrm{Pb}\left(\mathrm{NO}_{3}\right)_{2}$. Arrows indicate the increase in the concentration of $\mathrm{Pb}^{2+}$. Inset shows the Job plot for binding of $\mathrm{Pb}^{2+}$ to morin. (c) Fluorescence spectra of morin $(2.66 \times$ $\left.10^{-4} \mathrm{M}\right)$ in the presence of different concentrations $\left(0.75 \times 10^{-4}\right.$ to $\left.37.74 \times 10^{-4} \mathrm{M}\right)$ of $\mathrm{Pb}\left(\mathrm{NO}_{3}\right)_{2}\left(\lambda_{\text {ex }}=375 \mathrm{~nm}\right)$. Inset shows Stern-Volmer and modified Stern-Volmer plots for the interaction $\left(\lambda_{\mathrm{em}}=550 \mathrm{~nm}\right)$. (d) Time-resolved fluorescence transients of morin $\left(2.66 \times 10^{-4} \mathrm{M}\right)$ in the absence and presence of $\mathrm{Pb}^{2+}\left(37.7 \times 10^{-4} \mathrm{M}\right)$.

(GPx), we followed a modified method of Lawrence and Burk. ${ }^{39}$ To assess the extent of lipid peroxidation, the level of malonyldialdehyde (MDA), a substance that reacts with thiobarbituric acid, was determined in the homogenates of organs and in serum according to the method of Buege. ${ }^{40}$

Statistical Analysis. All quantitative data are expressed as mean \pm standard deviation (SD) unless otherwise stated. Oneway analysis of variance followed by Tukey's multiple comparison tests was executed for comparison of different parameters between the groups using a computer program GraphPad Prism (version 5.00 for Windows), GraphPad Software, California, USA. $p<0.05$ was considered significant.

\section{RESULTS AND DISCUSSION}

Interaction of Morin: A Model Flavonoid with HeavyMetal Lead $\left(\mathrm{Pb}^{2+}\right)$. Primarily, we chose morin $\left(3,5,7,2^{\prime}, 4^{\prime}\right.$ pentahydroxyflavone) (Figure 1a) as a representative of flavonoid class for understanding its heavy-metal chelating activity. Morin is very special among flavonols as it is one of those few natural flavonols that bears a $\mathrm{OH}$ group in position $2^{\prime}$ that can be involved in a hydrogen bond with $3-\mathrm{OH}$, leading to far reaching consequences. ${ }^{13}$ Despite being the most abundant polyphenol in our diet or in nature, this unique structural feature along with previously reported antiradical activity $^{41}$ made morin our molecule of interest. The absorbance spectra of morin (Figure 1b) show two absorption maxima centered at $\sim 255 \mathrm{~nm}$ (band II) and $\sim 354 \mathrm{~nm}$ (band I) corresponding to the $\Pi \rightarrow \Pi^{*}$ electronic transition originating at benzoyl (flavonoid ring A) and cinnamoyl (flavonoid ring B) systems, respectively. The interaction of morin with $\mathrm{Pb}^{2+}$ produced large bathochromatic shift $(\sim 45$ $\mathrm{nm}$ ) in band I maxima (Figure $1 \mathrm{~b}$ ). In contrast, band II remained unaffected. The exclusive change in band I indicates the involvement of cinnamoyl system in the complexation process. Among the three probable binding sites $(3-\mathrm{OH}$ and 4oxo, $3-\mathrm{OH}$ and $2^{\prime}-\mathrm{OH}$, or $5-\mathrm{OH}$ and 4-oxo) present in morin, $3-\mathrm{OH}$ and 4-oxo is the most preferable site of co-ordination because of the presence of highly acidic proton, stronger chelation ability, and greater delocalization of the oxygen at 3$\mathrm{OH}^{42,43}$ The stoichiometry of complexation was investigated by using Job's method (the method of continuous variation). ${ }^{44}$ Considering a global equilibrium of $\mathrm{Pb}$ (II) and $n$ ligands (L) on the form

$$
\mathrm{Pb}+n \mathrm{~L}=\mathrm{PbL}_{n}
$$

where $n$ is determined from the plot of the absorbance as a function of the mole fraction, $f$, of the added ligand. In the absorbance maximum

$$
n=\frac{f_{\max }}{1-f_{\max }}
$$

Inset of Figure $1 \mathrm{~b}$ represents a typical Job plot for the $\mathrm{Pb}$ (II)-morin system, in which the transition point for absorbance appeared at the molar fraction of 0.33 , suggesting that morin $(\mathrm{L})$ bound to $\mathrm{Pb}^{2+}$ with a $2: 1$ ratio in the complex 
Table 1. Fluorescence Lifetime Components of Polyphenols and $\mathrm{Pb}(\mathrm{II})-$ Polyphenol Complexes ${ }^{a}$

\begin{tabular}{|c|c|c|c|c|c|c|c|}
\hline & $\alpha_{1}(\%)$ & $\tau_{1}(\mathrm{ps})$ & $\alpha_{2}(\%)$ & $\tau_{2}(\mathrm{ps})$ & $\alpha_{3}(\%)$ & $\tau_{3}(\mathrm{ps})$ & $\langle\tau\rangle(\mathrm{ps})$ \\
\hline morin & 97.3 & 189.90 & 2.7 & 1858.50 & & & 234.95 \\
\hline morin- $\mathrm{Pb}(\mathrm{II})$ & 97.3 & 189.90 & 2.7 & 1858.00 & & & 234.95 \\
\hline naringin & & & 90.1 & 127.09 & 9.8 & 378.04 & 151.47 \\
\hline naringin $-\mathrm{Pb}(\mathrm{II})$ & 93.9 & 27.56 & 5.5 & 127.00 & 0.5 & 378.00 & 34.94 \\
\hline EA & & & 100 & 3072.45 & & & 3072.45 \\
\hline $\mathrm{EA}-\mathrm{Pb}(\mathrm{II})$ & 75.6 & 88.59 & 24.4 & 3072.00 & & & 816.54 \\
\hline MNEA-Pb(II) & 82.6 & 30.83 & 16.1 & 141.00 & 1.2 & 2088.84 & 73.22 \\
\hline SKP17LIV01 & 65.7 & 38.03 & 15.7 & 475.00 & 18.5 & 3156.55 & 683.52 \\
\hline SKP17LIV01-Pb(II) & 77.4 & 32.77 & 9.7 & 475.46 & 12.7 & 3156.00 & 472.32 \\
\hline
\end{tabular}

${ }^{a} \tau$ represents the time constant and $\alpha$ represents the relative contribution of the component. $\lambda_{\mathrm{ex}}=375 \mathrm{~nm}$ for all systems; $\lambda_{\mathrm{em}}(\mathrm{morin})=550 \mathrm{~nm}$; $\lambda_{\mathrm{em}}($ naringin $)=500 \mathrm{~nm} ; \lambda_{\mathrm{em}}(\mathrm{EA})=440 \mathrm{~nm} ; \lambda_{\mathrm{em}}($ MNEA $)=550 \mathrm{~nm} ; \lambda_{\mathrm{em}}(\mathrm{SKP} 17 \mathrm{LIV} 01)=550 \mathrm{~nm}$.

$\left(\mathrm{PbL}_{2}\right)$. The observed new band at $\sim 413 \mathrm{~nm}$ (Figure $1 \mathrm{~b}$ ) due to complexation corresponds to the formation of $\mathrm{Pb}-3-\mathrm{OH}$, forming a big extended $\Pi$-bonding system with the inclusion of $\mathrm{C}$ ring leading to further stabilization. ${ }^{45}$ The electronic transition within morin shifts from $n-\Pi^{*}$ to lower energy $\Pi-\Pi^{*}$ favoring the development of a new band at higher wavelength. ${ }^{46,49}$ The binding constant of the Morin- $\mathrm{Pb}^{2+}$ complex was found to be $1.803 \times 10^{4} \mathrm{M}^{-1}\left(R^{2}=0.987\right)$ using the Benesi-Hildebrand equation ${ }^{48}$

$$
\log \left(\frac{A-A_{0}}{A_{\mathrm{f}}-A_{0}}\right)=\log \left[\mathrm{Pb}^{2+}\right]+\log K_{\mathrm{b}}
$$

where, $A_{0}, A$, and $A_{\mathrm{f}}$ are the absorption values, in the absence of, at the intermediate, and at the saturation of the interaction of $\mathrm{Pb}^{2+}$ ion, respectively, and $\left[\mathrm{Pb}^{2+}\right]$ represents the concentration of aqueous $\mathrm{Pb}^{2+}$ ion added. The binding constant $\left(K_{\mathrm{b}}\right)$ was determined by linear fitting of absorption titration curve (Figure S1).

In the photoluminescence study, morin shows a strong emission at $\sim 550 \mathrm{~nm}$ when excited at $\sim 375 \mathrm{~nm}$ (Figure 1c). The observed fluorescence is probably originating from the anion form of the 7-OH group of the pyrone ring, as it gets deprotonated first owing to its low $\mathrm{pK}_{\mathrm{a}}$ of deprotonation $\left(\mathrm{p} K_{\mathrm{a}}\right.$ 3.80 ), and as a result, morin stays as monodepronated species in a solution of physiological $\mathrm{pH} .{ }^{49,50}$ In the presence of $\mathrm{Pb}^{2+}$, the fluorescence quenched (Figure 1c). The phenomenon of fluorescence quenching can be attributed to several molecular mechanisms including excited-state reactions, molecular rearrangements, energy transfer, ground-state complex formation, and collisional quenching. In the case of morin, no discernible shift in emission maxima $(\sim 550 \mathrm{~nm})$ or shape of the fluorescence spectrum accompanied quenching and the quenching behavior generally adhered to the Stern-Volmer equation (eq 1 ).

$$
\frac{F_{0}}{F}-1=K_{\mathrm{sv}}[\mathrm{Q}]=k_{\mathrm{q}} \tau_{0}[\mathrm{Q}]=\frac{\tau_{0}}{\tau}-1
$$

where $F_{0}$ and $F$ are the fluorescence intensities in the absence and presence of a quencher, $[\mathrm{Q}], K_{\mathrm{sv}}$ is the Stern-Volmer quenching constant, $k_{\mathrm{q}}$ is the bimolecular quenching rate constant, and $\tau_{0}$ and $\tau$ are the fluorescence lifetimes of the fluorophore in the absence and presence of the quencher, respectively. ${ }^{51}$ The linearity in the Stern-Volmer plot (Figure $1 c$, inset) indicates the existence of a single type of quenching, either static or dynamic. ${ }^{51}$ To get further insight into the phenomena, we measured the excited-state fluorescence lifetime of the fluorophore (morin) with increasing concentrations of the quencher, $\mathrm{Pb}^{2+}$ (Figure 1d). It is well-known that in the case of dynamic quenching, the fluorescence lifetime decreases with increasing concentrations. ${ }^{51}$ However, in this case, no change in fluorescence lifetime (Table 1) was observed, which clearly specifies the quenching mechanism to be static. This was further supported by the calculation of the bimolecular quenching constant, $k_{\mathrm{q}}\left(K_{\mathrm{sv}} / \tau_{0}\right)$, which was found to be $\sim 7.69 \times 10^{12} \mathrm{M}^{-1} \mathrm{~s}^{-1}$ higher than that of diffusioncontrolled limit $\left(\sim 10^{10} \mathrm{M}^{-1} \mathrm{~s}^{-1}\right){ }^{51}$ This along with no change in fluorescence lifetime indicates ground-state complex formation between $\mathrm{Pb}^{2+}$ and morin (association constant, $K_{\mathrm{a}}$ $=K_{\mathrm{sv}}=1.819 \times 10^{4} \mathrm{M}^{-1}$, similar to that found in the absorbance experiment). Probably, binding of $\mathrm{Pb}^{2+}$ to the carbonyl and $3-\mathrm{OH}$ groups of the pyrone ring inhibits the intramolecular proton transfer, resulting in the formation of a nonemissive or low-emission phototautomer at RT. ${ }^{50}$ Thus, it can be inferred from optical spectroscopic studies that morin acted as a bidentate ligand and formed a mononuclear complex with $\mathrm{Pb}^{2+}$, where one ion is bound to two ligands (Figure 2).

Interaction of Morin with $\mathrm{Pb}^{2+}$ in the Presence of Other Flavonoid Naringin and Polyphenol EA. Generally,

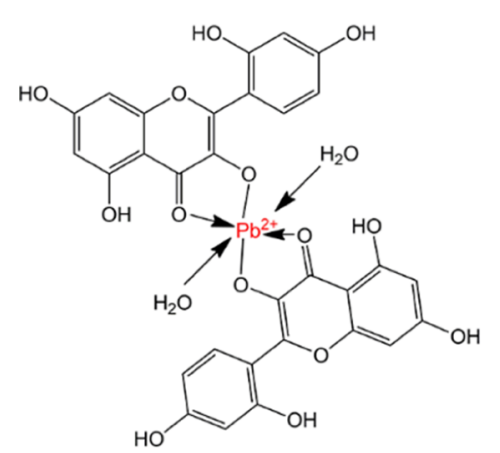

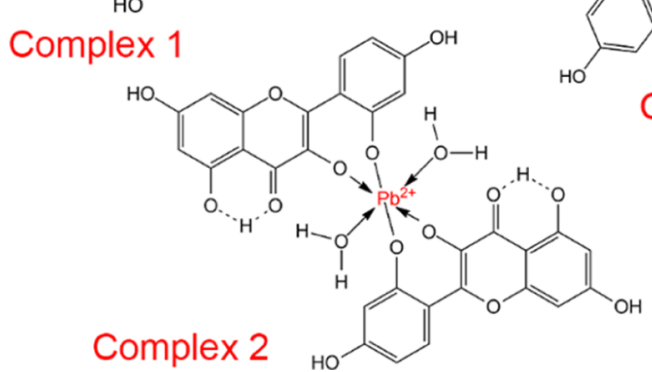

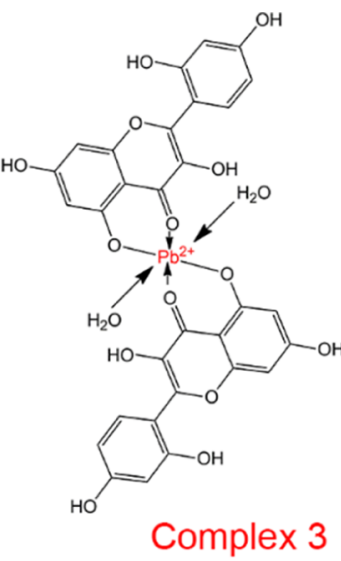

Figure 2. Three possible structures of morin $-\mathrm{Pb}^{2+}$ complex. Complex 1 is the most probable one. 

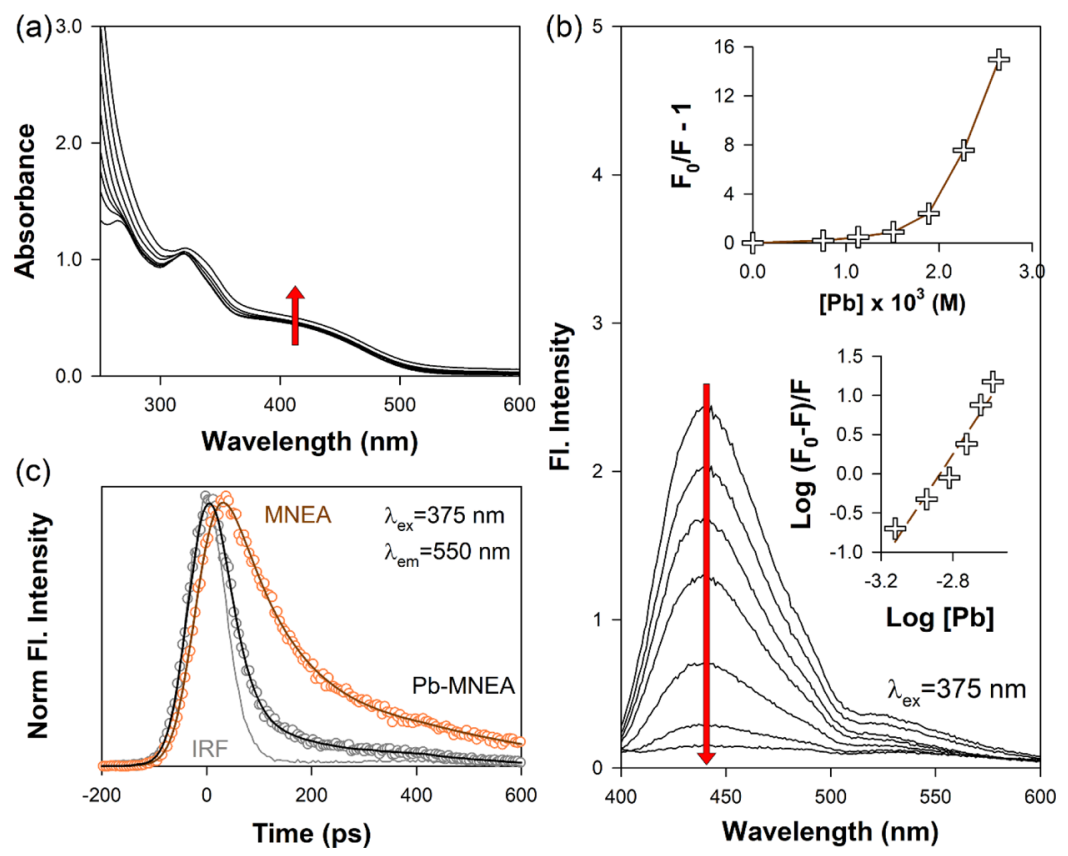

Figure 3. Interaction of $\mathrm{Pb}(\mathrm{II})$ with $\mathrm{MNEA}$, an equimolar mixture of three polyphenols morin (a flavanol), naringin (a flavonoid glycoside), and EA (an ellagitannin). (a) Absorption spectra of MNEA $\left(0.62 \times 10^{-4} \mathrm{M}\right)$ in the presence of varying concentrations $\left(0.91 \times 10^{-4}\right.$ to $\left.1.46 \times 10^{-4} \mathrm{M}\right)$ of $\mathrm{Pb}\left(\mathrm{NO}_{3}\right)_{2}$. Arrows indicate the increase in the concentration of $\mathrm{Pb}^{2+}$. (b) Fluorescence spectra of MNEA $\left(0.62 \times 10^{-4} \mathrm{M}\right)$ in the presence of different concentrations $\left(0.75 \times 10^{-4}\right.$ to $\left.30.19 \times 10^{-4} \mathrm{M}\right)$ of $\mathrm{Pb}\left(\mathrm{NO}_{3}\right)_{2}\left(\lambda_{\mathrm{ex}}=375 \mathrm{~nm}\right)$. Inset shows Stern-Volmer and modified Stern-Volmer plots for the interaction $\left(\lambda_{\mathrm{em}}=550 \mathrm{~nm}\right)$. (c) Time-resolved fluorescence transients of MNEA $\left(0.62 \times 10^{-4} \mathrm{M}\right)$ in the absence and presence of $\mathrm{Pb}^{2+}$ $\left(30.19 \times 10^{-4} \mathrm{M}\right)$.

in natural products, flavonoids never stay as a single entity, rather as a mixture of flavonoids and other polyphenols. Therefore, we prepared an equimolar mixture of morin, naringin (a flavonoid glycoside; Figure S1a), and EA (an ellagotannin; Figure S2a) to see whether the blending exerts any effect on heavy-metal binding property. Naringin and EA were selected as representatives of two different classes of polyphenols commonly found in natural products. Figure 3a shows the absorbance spectra of the mixture (we call it MNEA). Addition of $\mathrm{Pb}^{2+}$ to MNEA caused minimal or no change in absorbance. However, in fluorescence studies (Figure $3 \mathrm{~b}$ ), quenching phenomena was clearly evident at both $\lambda_{\mathrm{ex}}=450$ (probably originating from EA) and $\lambda_{\mathrm{ex}}=550$ $\mathrm{nm}$ (a tail probably originating from morin). Positive deviation of $F_{0} / F$ from linearity indicates the possible involvement of combined static and dynamic quenching. The Stern-Volmer constant for both types of quenching can be determined from equation (eq 2)

$$
\frac{F_{0}}{F}=\left(1+K_{\mathrm{D}}[\mathrm{Q}]\right)\left(1+K_{\mathrm{S}}[\mathrm{Q}]\right)
$$

where $K_{\mathrm{D}}$ is the dynamic quenching constant and $K_{\mathrm{S}}$ is the static quenching constant. The double logarithmic plot (Figure $3 \mathrm{~b}$, inset) reveals the association constant $\left(K_{\mathrm{a}}=3.16 \times 10^{4}\right.$ $\left.\mathrm{M}^{-1}\right)$ and number of binding sites $(n=1.25)$ using the following equation (eq 3 ).

$$
\log \frac{F_{0}-F}{F}=\log K_{\mathrm{a}}+n \log [\mathrm{Q}]
$$

where $K_{\mathrm{a}}$ is the association constant and $\mathrm{n}$ is the number of possible binding sites. The decrease in lifetime, as observed in TCSPC (Table 1), also supports our conjecture. The groundstate complex formation between morin and $\mathrm{Pb}^{2+}$, observed in the earlier section of this study, is primarily responsible for the static part of the observed quenching phenomena. To find out the origin of the dynamic quenching component, we further investigated the interaction of $\mathrm{Pb}^{2+}$ with the other two compounds in the mixture.

In the case of naringin (Figure S2a), as there was observable changes in the absorbance at $\lambda_{\mathrm{ex}}(375 \mathrm{~nm})$ or $\lambda_{\mathrm{em}}(500 \mathrm{~nm})$ (Figure S2b), we employed inner filter effect correction using the following equation (eq 4)

$$
F_{\text {obs }}=F_{\text {corr }} \times 10^{-A_{\text {ex }} \times d_{\mathrm{ex}} / 2-A_{\mathrm{em}} \times d_{\mathrm{em}} / 2}
$$

where $F_{\text {obs }}$ is the observed fluorescence intensity, $F_{\text {corr }}$ is the corrected fluorescence intensity after correction of inner filter effect, $d_{\mathrm{ex}}$ and $d_{\mathrm{em}}$ are the path lengths in the excitation and emission detection (in $\mathrm{cm}$ ), respectively, and $A_{\mathrm{ex}}$ and $A_{\mathrm{em}}$ are the detected changes in the absorbance value at the excitation and emission wavelengths, respectively, caused by ligand addition. $^{51,52}$ The Stern-Volmer plot (Figure S2d) constructed using the corrected fluorescence intensities showed linearity. The significant change in the lifetime (Table 1) describes the quenching process to be dynamic in nature. For EA (Figure S3a) also, the inner filter correction was employed because of the presence of significant change in absorbance (Figure $\mathrm{S} 3 \mathrm{~b}$ ). Addition of $\mathrm{Pb}^{2+}$ in the solution caused quenching of the fluorescence (Figure S3c) and the SternVolmer plot showed an upward curvature without any dependence onto $\left[\mathrm{Pb}^{2+}\right]$ (Figure S3d). Thus, neither simple dynamic (linear $F_{0} / F$, vs $\left[\mathrm{Pb}^{2+}\right]$ ) nor combined static and dynamic (second-degree polynomial) quenching model was accurately able to describe the data. Rather, a combined "sphere of action" dynamic quenching model was helpful. This includes, by means of a Poisson distribution, the probability

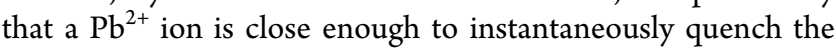


fluorescent species. ${ }^{51}$ This deviation from linear Stern-Volmer behavior is plausible for species such as $\mathrm{Pb}(\mathrm{II})$, where strong Coulombic interactions are likely to occur between the excited state and the quenching ion. ${ }^{53}$ This could further be supported from the time-resolved studies (Figure S3e), which shows a decrease in lifetime of the fluorophore (Table 1). The functional form of the quenching model is

$$
\frac{F_{0}}{F}=\left(1+K_{D}[Q]\right) \mathrm{e}^{\left(K_{e}[Q]\right)}
$$

The constants $K_{\mathrm{D}}$ and $K_{\mathrm{e}}$ were found by nonlinear leastsquares regression of the data. The dashed line in Figure S2d represents this model equation with the above empirical constants. Therefore, it can be concluded that the excited-state interaction between naringin- $\mathrm{Pb}$ (II) and $\mathrm{EA}-\mathrm{Pb}$ (II) is responsible for the observed dynamic quenching component of $\mathrm{MNEA}-\mathrm{Pb}$ (II) interaction. In order to investigate the mutual interaction among flavonoids and polyphenols, we have performed spectroscopic studies on the mixture. Although morin-naringin or naringin-EA shows insignificant changes in the steady-state emission and absorption spectroscopic data, mixing of morin with EA resulted in spectroscopic changes as shown in Figure S4a. The steady-state fluorescence spectra reveal the quenching at $550 \mathrm{~nm}$ with a subsequent increase at $450 \mathrm{~nm}$ with an iso-emissive point at $500 \mathrm{~nm}$ (Figure S4b). The Stern-Volmer plot (Figure S4b, inset) indicated the presence of a single type of quenching, which is found to be static in nature as fluorescence lifetime remained unchanged (Figure S4c). Thus, the flavonoids even in the presence of other polyphenols can effectively bind heavy metals and increase the detoxification possibility inside the body. The other polyphenols do not hamper the detoxification procedure rather shows a synergistic effect by chelating the heavy metal. In this process, as many of the polyphenols are potential $\mathrm{Pb}$ chelators, competition for metal complexation might occur between these natural chelators, resulting in synergistic effect.

Interaction of Flavonoids with Heavy Metal $\left(\mathrm{Pb}^{2+}\right)$ in Real-Life Sample, SKP17LIV01. Next, we proceed to a more complex mixture of flavonoids and polyphenols, SKP17LIV01 (total phenolic content $=4.71 \times 10^{-3} \mathrm{M}$; total flavonoid content $=3.97 \times 10^{-3} \mathrm{M}$; morin $=2.9 \%$, naringin $=1.2 \%$, and $\mathrm{EA}=1.8 \%)$. The mixture was completely characterized by UHPLC-MS (Figure 4). A summary of the results are described in the Supporting Information Datasheet SD1 and SD2. A detailed characterization and computational pharmacological analysis of the mixture are beyond the scope of this study and will be published elsewhere. Although it is hard to draw any conclusion from a mixture of $\sim 100$ polyphenols either by absorption or by emission, still we tried to find observable change (if any). In brief, the absorbance spectra of SKP17LIV01 show no or minimal changes upon gradual addition of $\mathrm{Pb}^{2+}$ (Figure 5a). However, in steady-state fluorescence spectra, quenching was observed (Figure 5b). The Stern-Volmer plot (Figure 5b, inset) suggests the presence of a single type of quenching, which is static in nature, as is also found from time-resolved studies (Figure 5c and Table 1). This is further supported by the calculation of the bimolecular quenching constant, $k_{\mathrm{q}}\left(K_{\mathrm{sv}} / \tau_{0}\right)$, which is found to be $\sim 4.81 \times 10^{12} \mathrm{M}^{-1} \mathrm{~s}^{-1}$ and higher than that of diffusion-controlled limit $\left(\sim 10^{10} \mathrm{M}^{-1} \mathrm{~s}^{-1}\right) .{ }^{51}$ The association constant $\left(K_{\mathrm{a}}\right)$ of SKP17LIV01 with $\mathrm{Pb}$ is found to be, $K_{\mathrm{a}}=$ $4.26 \times 10^{4} \mathrm{M}^{-1}$. It has to be noted that the mixture (SKP17LIV01) of flavonoids and lots of other polyphenols is

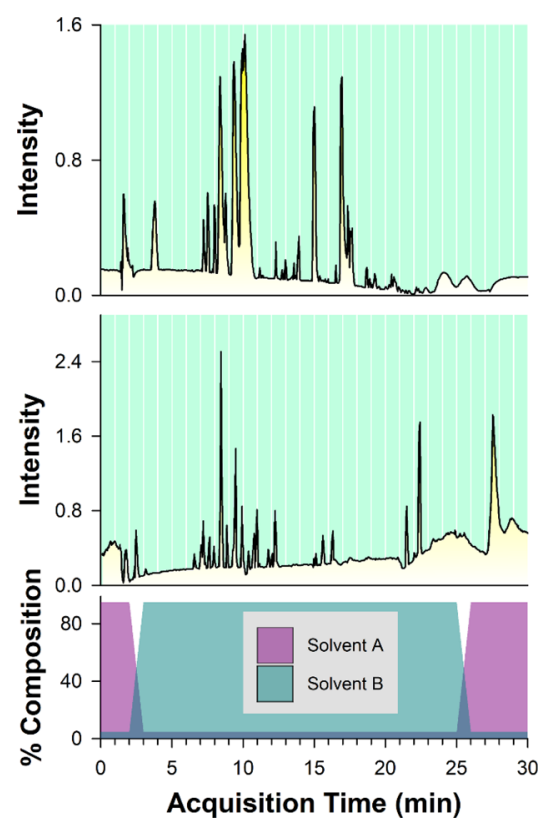

Figure 4. Determination of phytoconstituents in SKP17LIV01. HRLCMS analysis of the extract. Upper and middle panel shows the chromatogram in positive and negative mode, respectively. Lower panel shows the composition of solvent during the experiment.

able to retain the heavy-metal binding activity of constituent molecules. For the ease of extraction from medicinal plants, low cost, and efficient metal binding, the mixture is more attractive as a therapeutic agent than the individual compounds like morin or naringin.

Effect on Antioxidant Property of the Flavonoids after Heavy-Metal $\left(\mathrm{Pb}^{2+}\right)$ Chelation. Several studies suggested that polyphenols have a number of potential health benefits due, in part, to their antioxidant activity. $8,16,43,54,55$ Even in the case of heavy-metal toxicity, this property is vital along with chelation, as this would help to make the healing faster. Whether the flavonoid will retain the antioxidant property even after heavy-metal chelation was the major question. Therefore, we evaluated the antioxidant activity of model flavonoid, morin, before and after $\mathrm{Pb}$ (II) chelation using the DPPH assay. Figure 6a shows that morin was able to retain its free-radical scavenging activity even after $\mathrm{Pb}(\mathrm{II})$ chelation. The reaction between morin and DPPH occurs in two steps: (i) $\mathrm{DPPH}$ absorbance $\left(\lambda_{\max }=535 \mathrm{~nm}\right.$ in methanol) decays quickly (typical time, 60-120 s) and (ii) DPPH absorbance decays slowly in $\sim 1 \mathrm{~h}$ to reach a constant value. The fast step essentially refers to the abstractions of the most labile $\mathrm{H}$-atom from the antioxidant (3-OH in the case of morin), ${ }^{43,56}$ whereas the slow step reflects the remaining activity in the oxidationdegradation products. Binding of $\mathrm{Pb}^{2+}$ to morin slows down the process. The possible cause for this compromised freeradical scavenging activity may be the binding of $\mathrm{Pb}^{2+}$ to the 3$\mathrm{OH}$ of morin that results in abrogation in coplanarity and conjugation of the molecule. Previous studies have shown that planarity permits conjugation, electron dislocation, and a corresponding increase in the flavonoid phenoxyl radical stability. ${ }^{57,58}$ We further studied the recyclability of the compounds in DPPH radical scavenging (Figure $6 \mathrm{~b}-\mathrm{d}$ ). Interestingly, although morin scavenged the free radical very fast in the first cycle, it failed in successive cycles. In contrast, $\mathrm{Pb}^{2+}$-morin complex was able to sustainably scavenge free 

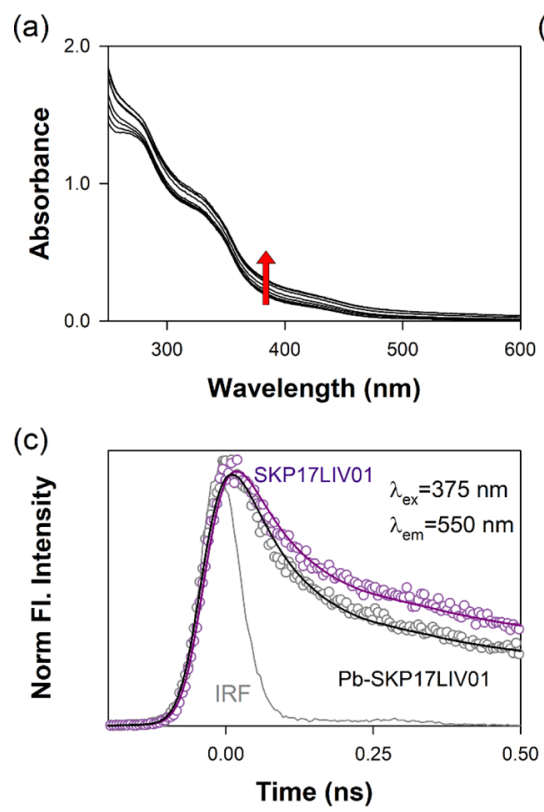

(b)

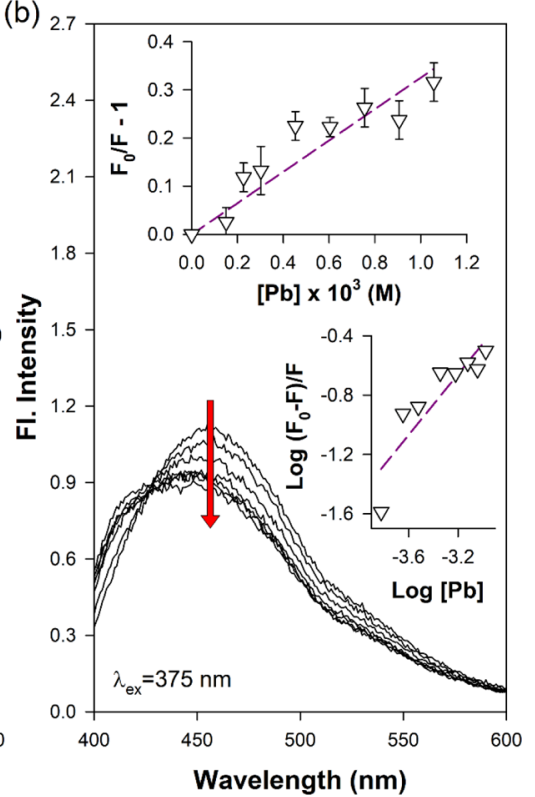

Figure 5. Interaction of $\mathrm{Pb}(\mathrm{II})$ with SKP17LIV01, an ethanolic plant extract containing numerous polyphenols (listed in the Supporting Information Dataset SD1 and SD2). (a) Absorption spectra of SKP17LIV01 in the presence of varying concentrations $\left(0.91 \times 10^{-4}\right.$ to $1.46 \times 10^{-4}$ $\mathrm{M})$ of $\mathrm{Pb}\left(\mathrm{NO}_{3}\right)_{2}$. Arrows indicate the increase in the concentration of $\mathrm{Pb}^{2+}$. (b) Fluorescence spectra of SKP17LIV01 in the presence of different concentrations $\left(0.75 \times 10^{-5}\right.$ to $\left.1.509 \times 10^{-4} \mathrm{M}\right)$ of $\mathrm{Pb}\left(\mathrm{NO}_{3}\right)_{2}\left(\lambda_{\mathrm{ex}}=375 \mathrm{~nm}\right)$. Inset shows Stern-Volmer and modified Stern-Volmer plots for the interaction $\left(\lambda_{\mathrm{em}}=550 \mathrm{~nm}\right)$. (c) Time-resolved fluorescence transients of SKP17LIV01 in the absence and presence of $\mathrm{Pb}^{2+}$.
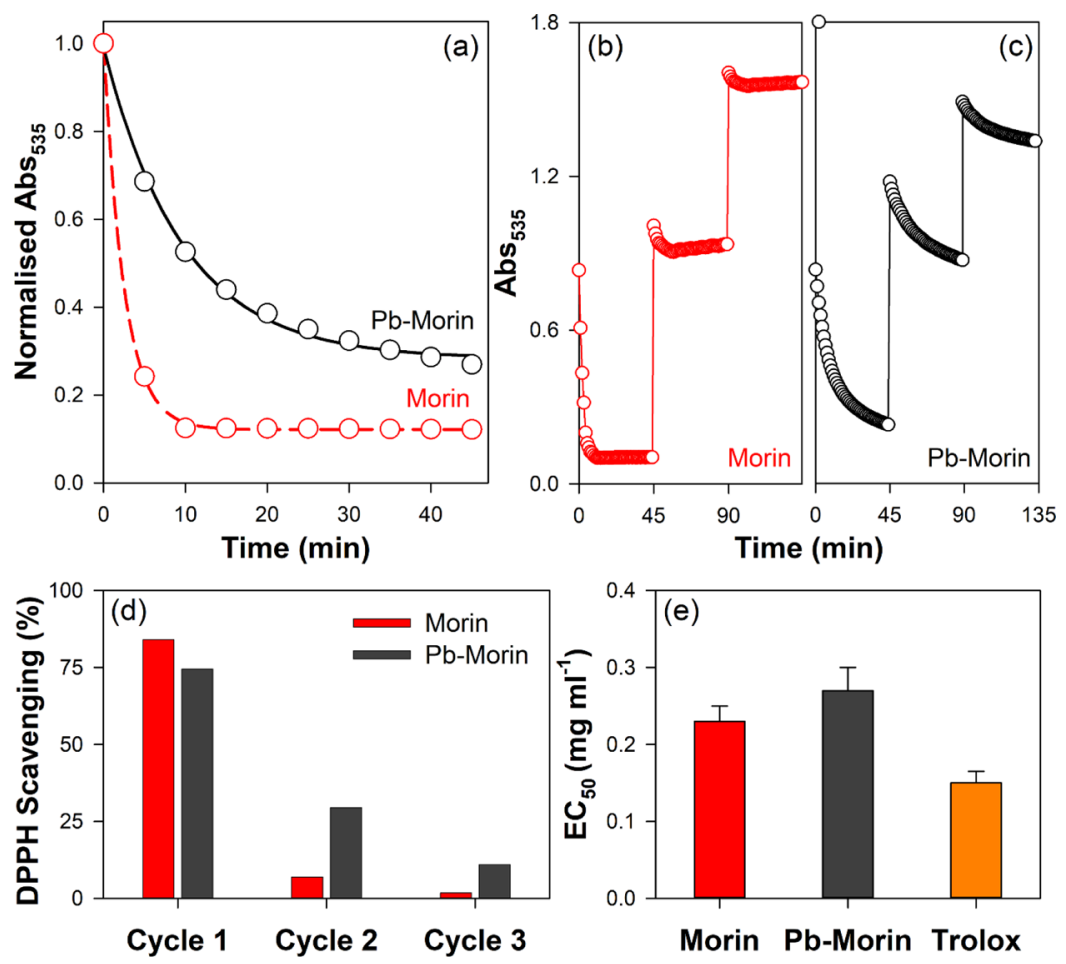

Figure 6. Antioxidant activity of polyphenols and mixtures. (a) Free-radical scavenging activity of morin before and after chelate formation as measured by the DPPH method. (b) Recyclability of morin and the chelate in DPPH scavenging. DPPH was added to the mixture in each 45 min and the degradation was monitored at $535 \mathrm{~nm}$. (d) DPPH radical scavenging activity of the compounds in each cycle. (e) $\mathrm{EC}_{50}$ values $\left(\mathrm{mg} \mathrm{mL}^{-1}\right)$ of morin, $\mathrm{Pb}(\mathrm{II})$-morin complex, and trolox (standard) for DPPH scavenging.

radicals up to three cycles. The $\mathrm{EC}_{50}$ value of $\mathrm{Pb}^{2+}$-morin complex remained almost the same as morin (Figure 6e), which further signifies the retention of antiradical activity even after heavy-metal chelation. This comes with an increase in the solubility of the chelate in aqueous media than that of free morin (Figure S5). It may be one of the causes of sustainable antioxidant activity of the chelate. The increased solubility is also important in quick removal of the heavy metal from the body. Similar results of sustainable antioxidant activity after $\mathrm{Pb}$ chelation were also obtained in the case of MNEA and 


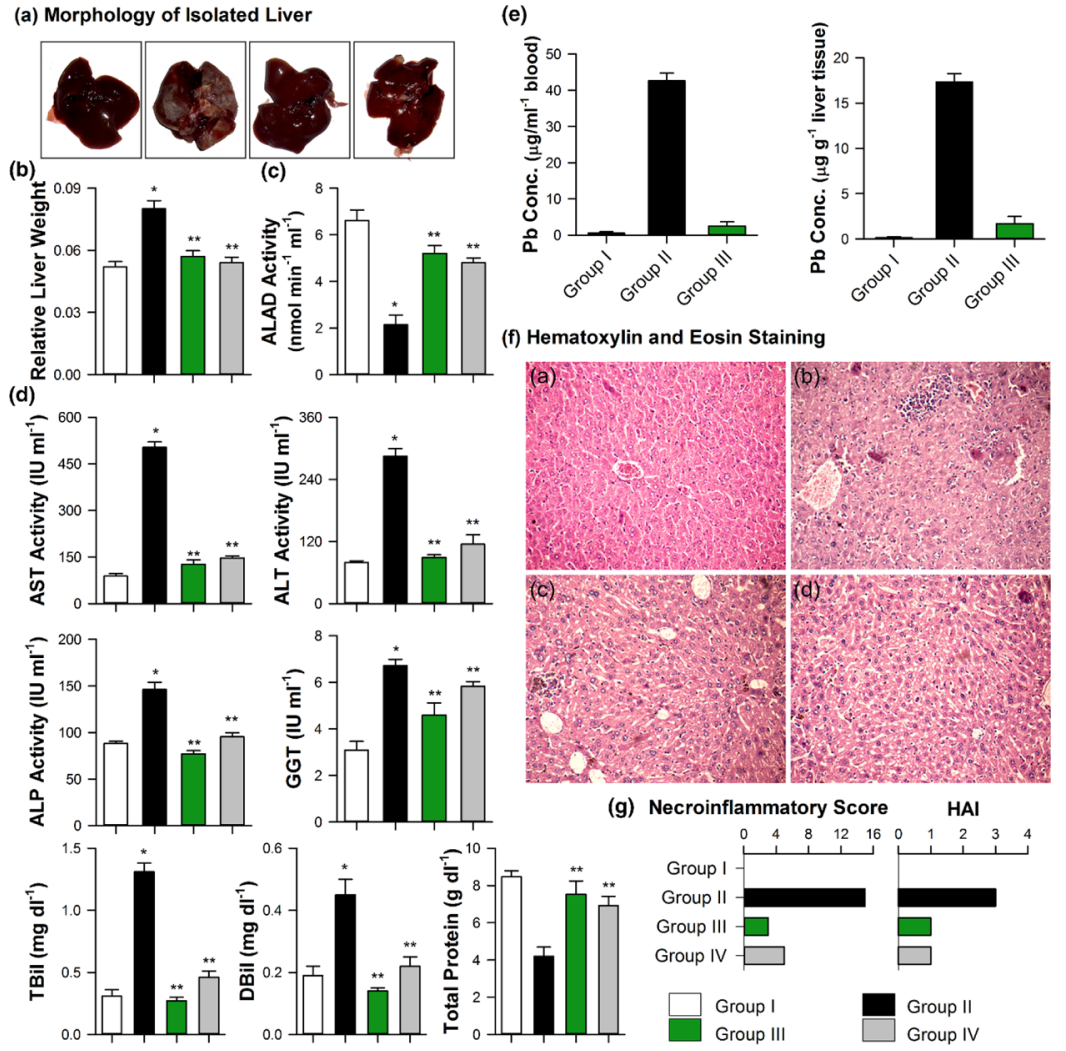

Figure 7. Effect of SKP17LIV01 on Pb(II)-intoxicated liver. (a) Morphology of the isolated livers. (b) Relative liver weight (liver weight to BW ratio) in the four groups of mice. (c) Change in the ALAD activity, a marker of Pb toxicity. (d) Results of liver function test. Serum AST, ALT, ALP, GGT, total bilirubin, direct bilirubin, and TP. (e) Distribution of $\mathrm{Pb}$ in blood and liver as investigated by the ICP-AES method after acid digestion. (f) Histopathological changes of liver from representative mice from each treatment group as observed after H\&E staining (original magnification 200X). The liver of mice treated with SKP17LIV01 did not show the inflammatory or necrotic features distinct in the $\mathrm{Pb}(\mathrm{II})$-treated group. (g) Necroinflammatory score and HAI. All data are presented as mean $\pm \mathrm{SD}(* P<0.05$ compared to control, $* * P<0.05$ compared to $\mathrm{Pb}(\mathrm{II})$-intoxicated group).

SKP17LIV01 (data not shown). Thus, the metal chelation imparted sustainability to the flavonoid as well as flavonoidpolyphenol mixtures in their antioxidant activity, leading to higher therapeutic efficacy.

Effect of SKP17LIV01, Real-Life Complex Flavonoid and Polyphenol Mixture, on in Vivo Mouse Model of $\mathrm{Pb}$ Toxicity. Diverse chemical assays have been developed with an aim to mimic the actual situation in human body. However, chemical models can be realistic assumptions only if a positive correlation between chemical and biological models is established. Therefore, we used an animal (Pb-intoxicated Swiss albino mouse) model that perfectly mimics the pathogenicity of heavy-metal-associated disorders, involving a complexity of physiological, immunological, environmental, and genetic phenomena. $\mathrm{Pb}$ intoxication causes severe damage to multiple organs leading to morbidity and mortality. According to many preceding studies, liver is one of the major target organs of $\mathrm{Pb}(\mathrm{II})$ toxicity. ${ }^{54,59,60}$ Figure 7 a shows the morphometric conditions of the isolated livers of different groups. Even from outside, there are visible damages to the liver isolated from $\mathrm{Pb}\left(\mathrm{NO}_{3}\right)_{2}$-treated mice. Absence of such signs in other groups indicates the healing effect of SKP17LIV01 as well as silymarin, the conventional drug. The observed enlargement of liver $(\sim 54 \%$ increase in liver weight to BW ratio compared to control; $p<0.05)$ in pathophysiological situation (Figure $7 \mathrm{~b}$ ) is well in agreement with previous studies. ${ }^{60}$ Increased proliferation of hepatocytes along with surge in cholesterol synthesis has been found to be associated with such hyperplastic effect of $\mathrm{Pb}$ on liver. ${ }^{60}$ Treatment with SKP17LIV01 reduced the relative liver weight ( $\sim 30 \%$ compared to group II; $p<0.05)$ to normal. One of the major ways $\mathrm{Pb}$ exerts its toxicity is through affecting the hematopoietic system by inhibition of ALAD. The activity of blood ALAD reduced significantly $(2.1 \pm 0.4$ compared to 6.2 $\pm 0.8 \mathrm{nmol} \mathrm{min}-1 \mathrm{~mL}^{-1}$ erythrocytes of control; $\left.p<0.001\right)$ in animals exposed to $\mathrm{Pb}$ (Figure 6c). The inhibition of ALAD was significantly less in animals administered with

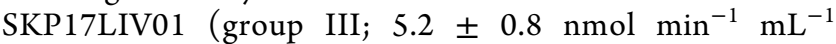
erythrocytes) and silymarin (group IV; $4.8 \pm 0.8 \mathrm{nmol}$ $\mathrm{min}^{-1} \mathrm{~mL}^{-1}$ erythrocytes). Treatment after $\mathrm{Pb}$ exposure with SKP17LIV01 was most effective in reversing blood ALAD inhibition ( $p<0.05$ compared to silymarin).

Serum aminotransferase activities have long been considered as sensitive indicators of hepatic injury. ${ }^{61,62}$ Injury to the hepatocytes alters their transport function and membrane permeability, leading to leakage of enzymes from the cells. ${ }^{63}$ As shown in Figure $6 \mathrm{~d}, 4$ weeks of $\mathrm{Pb}$ treatment increased the AST and ALT levels by 4.7-fold and 2.6-fold, respectively, compared to control $(p<0.001)$. This significant release of AST and ALT into the circulation indicates severe damage to hepatic tissue membranes due to chronic $\mathrm{Pb}$ exposure. Treatment with SKP17LIV01 produced dose-dependent reduction in AST and ALT levels (Table S3). In the final standardized dose, SKP17LIV01 was able to reduce the AST 


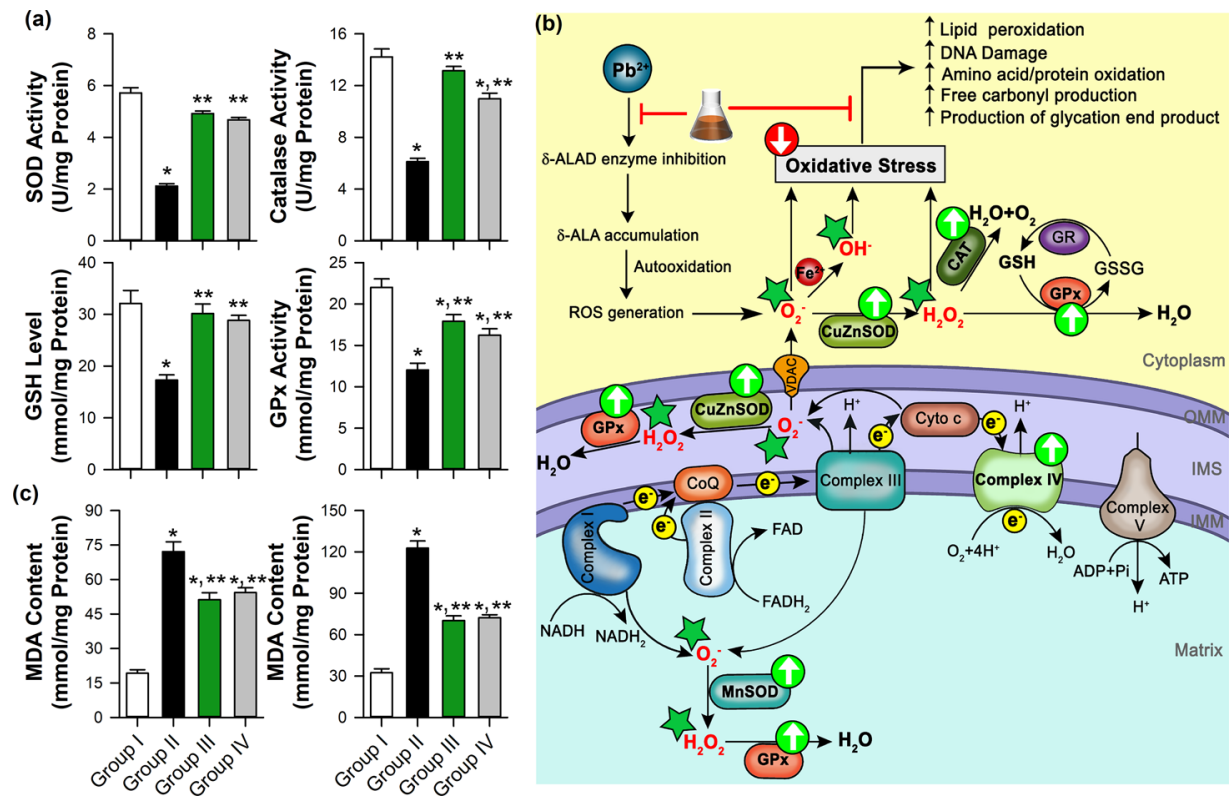

Figure 8. Molecular mechanism of action of SKP17LIV01 through redox modulatory activity. (a) Effect on cellular antioxidant system. (b) Schematic representation of the mechanism of action of SKP17LIV01 on antioxidant system (SOD, CAT, GSH, and GPx). (c) Effect on lipid peroxidation. All data are presented as mean $\pm \mathrm{SD}(* P<0.05$ compared to control, $* * P<0.05$ compared to $\mathrm{Pb}$ (II)-intoxicated group).

and ALT levels by 75 and $70 \%$, respectively, compared to the $\mathrm{Pb}$-intoxicated group $(p<0.001)$. Previous studies suggest that returning of aminotransferase levels to normalcy is associated with the healing of liver parenchyma and regeneration of hepatocytes. ${ }^{63}$ There was also surges in other liver function parameters such as ALP $(\sim 66 \%)$, GGT $(\sim 120 \%)$, total bilirubin $(\sim 320 \%)$, direct bilirubin $(\sim 135 \%)$, and marked decrease in TP concentration $(\sim 50 \%)$ in Pb-treated group ( $p$ $<0.001$ compared to the normal ones). Treatment with SKP17LIV01 recovers all the parameters to normal levels (Figure $7 \mathrm{~b}$ ).

As described in Figure 6e, $\mathrm{Pb}\left(\mathrm{NO}_{3}\right)_{2}$ exposure increased $\mathrm{Pb}$ levels both in the blood and liver of mice $(17.34 \pm 0.91 \mu \mathrm{g}$ $\mathrm{mL}^{-1}$ and $42.63 \pm 2.1 \mu \mathrm{g} \mathrm{g}^{-1}$, respectively) compared to control $\left(0.13 \pm 0.09 \mu \mathrm{g} \mathrm{mL}{ }^{-1}\right.$ and $0.58 \pm 0.11 \mu \mathrm{g} \mathrm{g}^{-1}$, respectively; $p<0.001)$. We hereby found that SKP17LIV01 significantly decreased $\mathrm{Pb}$ in the blood and liver $(1.69 \pm 0.05$ $\mu \mathrm{g} \mathrm{mL}^{-1}$ and $2.58 \pm 0.2 \mu \mathrm{g} \mathrm{g}^{-1}$, respectively; $\left.p<0.001\right)$. This is consistent with our in vitro spectroscopic studies, where the ability of SKP17LIV01 to chelate $\mathrm{Pb}^{2+}$ is found. The microscopic images of $\mathrm{H}$ \& E-stained liver sections are depicted in Figure 7f. The control group (group I) showed normal hepatocytes and nuclei where the hepatic lobules are hexagonal, clearly distinguishable, separated by interlobular septa, and traversed by portal veins. In Pb-treated animals, the remarkable degenerative histological changes of liver, such as structural damage, disorganization of hepatic chords, cytoplasmic vacuolation, hepatocellular necrosis, leukocyte infiltration, and massive hemorrhage had been observed. ${ }^{64}$ The SKP17LIV01-treated $\mathrm{Pb}$ intoxicated mice (group III) showed almost normal hepatocytes with a mild degree of mononuclear infiltration and necrosis, almost comparable to the control. The significant tissue damage induced by $\mathrm{Pb}\left(\mathrm{NO}_{3}\right)_{2}$ intoxication might be attributed to its ability to generate ROS that induce oxidative damage in several tissues by enhancing lipid peroxidation. ${ }^{59}$ Also, the degradative effect of $\mathrm{Pb}$ on cellular enzymes, particularly those associated with energy production, leads to hydropic degeneration of mitochondria and causes cytoplasmic vacuolization. ${ }^{65}$ We applied modified Ishak and METAVIR histological activity index (HAI) (Figure $7 \mathrm{~g}$ ) to assess the necroinflammatory damage caused by $\mathrm{Pb}(\mathrm{II})$. The $\mathrm{Pb}$-intoxicated animals scored 15 and 3 (the maximum possible score is 16 and 3), where SKP17LIV01 treatment decreased it to 3 and 0 . Thus, as evident from the microscopic images, SKP17LIV01 is able to protect and preserve the normal liver structure even better than conventional drug silymarin.

The circulatory system is one of the target organs of $\mathrm{Pb}$ toxicity. ${ }^{66}$ The results concerning hematological parameters (Table S4) showed a significant $(p<0.001)$ decline in total erythrocyte count, total leukocyte count, $\mathrm{Hb}$ concentration, lymphocyte, and monocyte content in the $\mathrm{Pb}\left(\mathrm{NO}_{3}\right)_{2}$-treated animals (group II), in comparison to control animals ( $p<$ $0.05)$, whereas neutrophil content insignificantly increased in $\mathrm{Pb}\left(\mathrm{NO}_{3}\right)_{2}$-treated group, when compared with control animals $(p<0.05)$. Recovery of the above-mentioned parameters is observed in the SKP17LIV01-treated group.

Mechanism Behind the in Vivo Protective Effect of SKP17LIV01 Against Pb Toxicity. A number of in vitro and in vivo studies indicated that $\mathrm{Pb}$ causes oxidative stress by inducing the generation of ROS, including hydroperoxides, singlet oxygen, hydrogen peroxide, and superoxide. It has also been observed that $\mathrm{Pb}$ can decrease antioxidant enzymatic activity in liver. ${ }^{54}$ In the present study, the increase in hepatic ROS production manifested in the depletion of SOD, CAT, and GPx levels, the major enzyme triad responsible for scavenging of free radicals inside the body. To be particular, SOD converts superoxide anions to $\mathrm{H}_{2} \mathrm{O}_{2}$, which is further converted to $\mathrm{H}_{2} \mathrm{O}$ with the help of GPx and CAT. ${ }^{67}$ In this study, 4 weeks of chronic $\mathrm{Pb}$ exposure decreased these enzyme levels by 63,57 , and $45 \%$, respectively, compared to control group $(p<0.05)$ and caused severe oxidative damage to the liver cells. However, treatment with SKP17LIV01 helped the $\mathrm{Pb}$-intoxicated mice to replenish their antioxidant enzyme system to normal (increase in SOD $\sim 132 \%$, CAT $~ 115 \%$, and GPx $\sim 50 \% ; p<0.05$ in all cases) (Figure 8a,b). 
Thiol-based antioxidant system plays second line of cellular protection against reactive free-radical-mediated oxidative damage in pathophysiological situation. ${ }^{54}$ Cellular metabolite such as GSH has been presented in Figure 8a. The level of GSH has been considerably decreased because of intoxication along with the increased level of oxidized glutathione. Posttreatment with SKP17LIV01 after the $\mathrm{Pb}$ (II) exposure restored the levels of cellular metabolites close to normal, demonstrating its protective nature. Figure $8 \mathrm{~b}$ provides a schematic overview of the proposed mechanism of action of SKP17LIV01 in the protection of oxidative stress induced by $\mathrm{Pb}$. The model clearly indicates that SKP17LIV01, despite direct sustainable free-radical scavenging activity, boosts the in vivo enzymatic antioxidant defense system resulting in protection from increased levels of ROS. The model is further supported by the observations of lipid peroxidation and protein carbonylation, the two important markers of oxidative stress. The increase in the MDA level (Figure $8 \mathrm{c}$ ) in the serum and liver $(\sim 3.8$ fold compared to control in both cases, $p<0.01)$ upon $\mathrm{Pb}\left(\mathrm{NO}_{3}\right)_{2}$ treatment suggests enhanced peroxidation, leading to tissue damage and failure of antioxidant mechanism to prevent the formation of excessive free radicals. Post-treatment with SKP17LIV01 $\left(\mathrm{Pb}\left(\mathrm{NO}_{3}\right)_{2}+\right.$ SKP17LIV01) significantly attenuated these changes (decrease in MDA level by $\sim 1.8$ folds (liver) and $\sim 1.5$-folds (serum) compared to $\mathrm{PbNO}_{3}$ treated group, $p<0.05$ in all cases). The flavonoids and polyphenols exert their antioxidant effects in the body by preventing the generation of ROS, direct scavenging of it, or through enhancement of cellular antioxidant system. Thus, the observed recovery of antioxidant enzyme pool in the animal model of $\mathrm{Pb}$ intoxication after the administration of SKP17LIV01 is the consequence of synergistic activity between its various phytoconstituents as evident from our spectroscopic studies. The flavonoids may have played a crucial role in the reduction of the treatment period by controlling the accumulation and bioavailability of $\mathrm{Pb}$ (II) in the tissue through complexation, subsequent sustainable antioxidant activity, and removal.

\section{CONCLUSIONS}

The disaster due to $\mathrm{Pb}$ poisoning is evident from the ancient human civilization till date, although it is concluded to be preventable. Understanding the mechanism of $\mathrm{Pb}$ detoxification by low-cost medicinally important molecules and costeffective herbal mixture is very important for the promotion of lots of folk medicines in developing countries. Here, we have explored the detailed mechanism of $\mathrm{Pb}$ detoxification by morin, a model flavonoid, which is omnipresent in medicinal herbs using steady-state and picosecond-resolved optical spectroscopy. We have shown that $\mathrm{Pb}$-morin chelate becomes a sustainable antioxidant revealing dual role of the flavonoid in the heavy-metal detoxification process. Our spectroscopic studies also reveal that the dual nature in the detoxification remains intact in the controlled mixture of few flavonoid and polyphenol molecules (MNEA), and even in a mixture, many such molecules were extracted from medicinal plants (SKP17LIV01). We have studied the efficacy of the complex mixture in the mouse model for the detoxification of $\mathrm{Pb}$ poisoning in detail. Subsequent, biochemical, histopathological, and biodistribution studies confirm that the molecular mixture (SKP17LIV01) facilitates excretion of $\mathrm{Pb}$ from the mammal (mice) body after heavy-metal chelation and ROS scavenging. The study is expected to have an impact in the discovery of new drugs of ethnobotanical origin.

\section{ASSOCIATED CONTENT}

\section{Supporting Information}

The Supporting Information is available free of charge on the ACS Publications website at DOI: 10.1021/acsomega.8b02046.

Composition of ingredient(s) present in SKP17LIV01, AST and ALT activity, summary of the hematological parameters, determination of binding constant of the $\mathrm{Pb}(\mathrm{II})-$ Morin complex, interaction of $\mathrm{Pb}(\mathrm{II})$ with narigin, interaction of $\mathrm{Pb}$ (II) with $\mathrm{EA}$, interaction of EA with morin, effect of $\mathrm{Pb} 2+$ chelation on aqueous solubility of morin, compounds and metabolites identified in positive mode, compounds and metabolites identified in negative mode of UHPLC-MS (PDF)

\section{AUTHOR INFORMATION}

\section{Corresponding Author}

*E-mail: skpal@bose.res.in (S.K.P.).

ORCID $\odot$

Samir Kumar Pal: 0000-0001-6943-5828

Author Contributions

${ }^{\perp}$ A.A. and S.D. contributed equally.

Notes

The authors declare no competing financial interest.

\section{ACKNOWLEDGMENTS}

The authors thank DAE (India) for financial grant, 2013/37P/ 73/BRNS and DST, India, for financial grants, SB/S1/PC$011 / 2013$. The authors also thank DBT (WB)-BOOST scheme for financial grant, 339/WBBDC/1P-2/2013. The authors thank SAIF, IIT Bombay, for performing HR-LCMS and estimating the $\mathrm{Pb}$ content of liver and blood by ICP-AES. The authors would like to thank Anindita Bhattacharya for careful reading of the manuscript and subsequent modifications.

\section{REFERENCES}

(1) Tong, S.; von Schirnding, Y. E.; Prapamontol, T. Environmental lead exposure: a public health problem of global dimensions. Bull. $W$. H. O. 2000, 78, 1068-1077.

(2) Papanikolaou, N. C.; Hatzidaki, E. G.; Belivanis, S.; Tzanakakis, G. N.; Tsatsakis, A. M. Lead toxicity update. A brief review. Med. Sci. Monit. 2005, 11, RA329-RA336.

(3) Dua, T. K.; Dewanjee, S.; Khanra, R.; Joardar, S.; Barma, S.; Das, S.; Zia-Ul-Haq, M.; De Feo, V. Cytoprotective and Antioxidant Effects of an Edible Herb, Enhydra fluctuans Lour. (Asteraceae), against Experimentally Induced Lead Acetate Intoxication. PLoS One 2016, 11, e0148757.

(4) Hsu, P.; Guo, Y. L. Antioxidant nutrients and lead toxicity. Toxicology 2002, 180, 33-44.

(5) Dapul, H.; Laraque, D. Lead Poisoning in Children. Adv. Pediatr. 2014, 61, 313-333.

(6) WHO International lead poisoning prevention week of action. http://www.who.int/ipcs/lead campaign/en/, http://www.who.int/ ipcs/lead campaign/en/ (accessed July 25, 2018).

(7) WHO. Childhood Lead Poisoning; World Health Organization: Geneva, Switzerland, 2010; $\mathrm{p} 74$.

(8) Chander, K.; Vaibhav, K.; Ahmed, M. E.; Javed, H.; Tabassum, R.; Khan, A.; Kumar, M.; Katyal, A.; Islam, F.; Siddiqui, M. S. Quercetin mitigates lead acetate-induced behavioral and histological 
alterations via suppression of oxidative stress, Hsp-70, Bak and upregulation of Bcl-2. Food Chem. Toxicol. 2014, 68, 297-306.

(9) Gurer, H.; Ercal, N. Can antioxidants be beneficial in the treatment of lead poisoning? Free Radical Biol. Med. 2000, 29, 927945.

(10) Dewanjee, S.; Sahu, R.; Karmakar, S.; Gangopadhyay, M. Toxic effects of lead exposure in Wistar rats: involvement of oxidative stress and the beneficial role of edible jute (Corchorus olitorius) leaves. Food Chem. Toxicol. 2013, 55, 78-91.

(11) Xia, D.; Yu, X.; Liao, S.; Shao, Q.; Mou, H.; Ma, W. Protective effect of Smilax glabra extract against lead-induced oxidative stress in rats. J. Ethnopharmacol. 2010, 130, 414-420.

(12) Kumar, S.; Pandey, A. K. Chemistry and Biological Activities of Flavonoids: An Overview. Sci. World J. 2013, 2013, 162750.

(13) Moncomble, A.; Thaviligadu, D. J.; Djendja, A. R.; Cornard, J.$P$. The crucial role of the inter-ring hydrogen bond to explain the properties of morin. New J. Chem. 2018, 42, 7691-7702.

(14) Hidalgo, M.; Sánchez-Moreno, C.; de Pascual-Teresa, S. Flavonoid-flavonoid interaction and its effect on their antioxidant activity. Food Chem. 2010, 121, 691-696.

(15) Plumb, G. W.; De Pascual-Teresa, S.; Santos-Buelga, C.; Cheynier, V.; Williamson, G. Antioxidant properties of catechins and proanthocyanidins: Effect of polymerisation, galloylation and glycosylation. Free Radical Res. 1998, 29, 351-358.

(16) Rice-Evans, C. A.; Miller, N. J.; Paganga, G. Structureantioxidant activity relationships of flavonoids and phenolic acids. Free Radical Biol. Med. 1996, 20, 933-956.

(17) Plumb, G. W.; Chambers, S. J.; Lambert, N.; Bartolomé, B.; Heaney, R. K.; Wanigatunga, S.; Aruoma, O. I.; Halliwell, B.; Williamson, G. Antioxidant actions of fruit, herb and spice extracts. J. Food Lipids 1996, 3, 171-188.

(18) Mateos, R.; Domínguez, M. M.; Espartero, J. L.; Cert, A. Antioxidant effect of phenolic compounds, $\alpha$-tocopherol, and other minor components in virgin olive oil. J. Agric. Food Chem. 2003, 51, $7170-7175$

(19) García-Alonso, M.; Rimbach, G.; Rivas-Gonzalo, J. C.; de Pascual-Teresa, S. Antioxidant and cellular activities of anthocyanins and their corresponding vitisins A-studies in platelets, monocytes, and human endothelial cells. J. Agric. Food Chem. 2004, 52, 33783384.

(20) Bagchi, D.; Chaudhuri, S.; Sardar, S.; Choudhury, S.; Polley, N.; Lemmens, P.; Pal, S. K. Modulation of stability and functionality of a phyto-antioxidant by weakly interacting metal ions: curcumin in aqueous solution. RSC Adv. 2015, 5, 102516-102524.

(21) Samsonowicz, M.; Regulska, E. Spectroscopic study of molecular structure, antioxidant activity and biological effects of metal hydroxyflavonol complexes. Spectrochim. Acta, Part A 2017, 173, 757-771.

(22) Cornard, J. P.; Merlin, J. C. Comparison of the chelating power of hydroxyflavones. J. Mol. Struct. 2003, 651-653, 381-387.

(23) Michalak, A. Phenolic compounds and their antioxidant activity in plants growing under heavy metal stress. Pol. J. Environ. Stud. 2006, $15,523$.

(24) Barceló, J.; Poschenrieder, C. Fast root growth responses, root exudates, and internal detoxification as clues to the mechanisms of aluminium toxicity and resistance: a review. Environ. Exp. Bot. 2002, $48,75-92$.

(25) Keilig, K.; Ludwig-Müller, J. Effect of flavonoids on heavy metal tolerance in Arabidopsis thaliana seedlings. Bot. Stud. 2009, 50, 311318.

(26) Mira, L.; Fernandez, M. T.; Santos, M.; Rocha, R.; Florêncio, M. H.; Jennings, K. R. Interactions of Flavonoids with Iron and Copper Ions: A Mechanism for their Antioxidant Activity. Free Radical Res. 2002, 36, 1199-1208.

(27) Dávila, Y. A.; Sancho, M. I.; Almandoz, M. C.; Gasull, E. Spectroscopic and Electronic Analysis of Chelation Reactions of Galangin and Related Flavonoids with Nickel(II). J. Chem. Eng. Data 2018, 63, 1488-1497.
(28) Kuntić, V.; Filipović, I.; Vujić, Z. Effects of rutin and hesperidin and their $\mathrm{Al}(\mathrm{III})$ and $\mathrm{Cu}(\mathrm{II})$ complexes on in vitro plasma coagulation assays. Molecules 2011, 16, 1378-1388.

(29) Chen, X.; Tang, L.-J.; Sun, Y.-N.; Qiu, P.-H.; Liang, G. Syntheses, characterization and antitumor activities of transition metal complexes with isoflavone. J. Inorg. Biochem. 2010, 104, 379-384.

(30) Kasprzak, M. M.; Erxleben, A.; Ochocki, J. Properties and applications of flavonoid metal complexes. RSC Adv. 2015, 5, 4585345877.

(31) Chen, W.; Sun, S.; cao, W.; Liang, Y.; Song, J. Antioxidant property of quercetin-Cr(III) complex: The role of $\mathrm{Cr}$ (III) ion. J. Mol. Struct. 2009, 918, 194-197.

(32) Mao, S.; Wang, K.; Lei, Y.; Yao, S.; Lu, B.; Huang, W. Antioxidant synergistic effects of Osmanthus fragrans flowers with green tea and their major contributed antioxidant compounds. Sci. Rep. 2017, 7, 46501.

(33) Dai, F.; Chen, W.-F.; Zhou, B. Antioxidant synergism of green tea polyphenols with $\alpha$-tocopherol and 1-ascorbic acid in SDS micelles. Biochimie 2008, 90, 1499-1505.

(34) Berlin, A.; Schaller, K. H. European standardized method for the determination of delta-aminolevulinic acid dehydratase activity in blood. Z Klin Chem Klin Biochem. 1974, 12, 389-390.

(35) Khandelwal, P.; Alam, A.; Choksi, A.; Chattopadhyay, S.; Poddar, P. Retention of Anticancer Activity of Curcumin after Conjugation with Fluorescent Gold Quantum Clusters: An in Vitro and in Vivo Xenograft Study. ACS Omega 2018, 3, 4776-4785.

(36) Kakkar, P.; Das, B.; Viswanathan, P. N. A modified spectrophotometric assay of superoxide dismutase. Indian J. Biochem. Biophys. 1984, 21, 130-132.

(37) Maehly, A. C.; Chance, B. The assay of catalases and peroxidases. Methods Biochem. Anal. 1954, 1, 357-424.

(38) Sedlak, J.; Lindsay, R. H. Estimation of total, protein-bound, and nonprotein sulfhydryl groups in tissue with Ellman's reagent. Anal. Biochem. 1968, 25, 192-205.

(39) Burk, R. F.; Trumble, M. J.; Lawrence, R. A. Rat hepatic cytosolic glutathione-dependent enzyme protection against lipid peroxidation in the nadph-microsomal lipid peroxidation system. Biochim. Biophys. Acta Lipids Lipid Metab. 1980, 618, 35-41.

(40) Buege, J. A.; Aust, S. D. Microsomal lipid peroxidation. In Methods in Enzymology; Fleischer, S., Packer, L., Eds.; Academic Press, 1978; Vol. 52, pp 302-310.

(41) Marković, Z.; Milenković, D.; Đorović, J.; Marković, J. M. D.; Stepanić, V.; Lučić, B.; Amić, D. PM6 and DFT study of free radical scavenging activity of morin. Food Chem. 2012, 134, 1754-1760.

(42) Panhwar, Q. K.; Memon, S. Synthesis and evaluation of antioxidant and antibacterial properties of morin complexes. J. Coord. Chem. 2011, 64, 2117-2129.

(43) Jovanovic, S. V.; Steenken, S.; Tosic, M.; Marjanovic, B.; Simic, M. G. Flavonoids as Antioxidants. J. Am. Chem. Soc. 1994, 116, 48464851.

(44) Renny, J. S.; Tomasevich, L. L.; Tallmadge, E. H.; Collum, D. B. Method of continuous variations: applications of job plots to the study of molecular associations in organometallic chemistry. Angew. Chem., Int. Ed. 2013, 52, 11998-12013.

(45) Ensafi, A. A.; Hajian, R.; Ebrahimi, S. Study on the interaction between morin-Bi (III) complex and DNA with the use of methylene blue dye as a fluorophor probe. J. Braz. Chem. Soc. 2009, 20, $266-$ 276.

(46) Silva, M. M.; Santos, M. R.; Caroço, G.; Rocha, R.; Justino, G.; Mira, L. Structure-antioxidant activity relationships of flavonoids: a reexamination. Free Radical Res. 2002, 36, 1219-1227.

(47) Panhwar, Q. K.; Memon, S. Synthesis and properties of zirconium(IV) and molybdate(II) morin complexes. J. Coord. Chem. 2012, 65, 1130-1143.

(48) Roy, D.; Chakraborty, A.; Ghosh, R. Perimidine based selective colorimetric and fluorescent turn-off chemosensor of aqueous $\mathrm{Cu} 2+$ : studies on its antioxidant property along with its interaction with calf thymus-DNA. RSC Adv. 2017, 7, 40563-40570. 
(49) Binbuga, N.; Hasty, J. K.; Gwaltney, S. R.; Henry, W. P.; Schultz, T. P. Determination of the stability constants for the binding of sulfonated morin with Fe2+. Inorg. Chim. Acta 2007, 360, 23392344.

(50) Gutierrez, A. C.; Gehlen, M. H. Time resolved fluorescence spectroscopy of quercetin and morin complexes with $\mathrm{Al} 3+$. Spectrochim. Acta, Part A 2002, 58, 83-89.

(51) Lackowicz, J. Principles of Fluorescence Spectroscopy; Springer Science+ Business Media, LLC: New York, 2006; Vol. 13, pp 978980.

(52) van de Weert, M.; Stella, L. Fluorescence quenching and ligand binding: A critical discussion of a popular methodology. J. Mol. Struct. 2011, 998, 144-150.

(53) Auger, R. L.; Jacobson, A. M.; Domach, M. M. Aqueous Phase Fluorescence Quenching Technique for Measuring Naphthalene Partition Coefficients in Nonionic Surfactant Micelles. Environ. Sci. Technol. 1995, 29, 1273-1278.

(54) Pal, P. B.; Sinha, K.; Sil, P. C. Mangiferin, a Natural Xanthone, Protects Murine Liver in $\mathrm{Pb}$ (II) Induced Hepatic Damage and Cell Death via MAP Kinase, NF- $\kappa \mathrm{B}$ and Mitochondria Dependent Pathways. PLoS One 2013, 8, e56894.

(55) Manna, P.; Bhattacharyya, S.; Das, J.; Ghosh, J.; Sil, P. C. Phytomedicinal Role of Pithecellobium dulce against CCl4-mediated Hepatic Oxidative Impairments and Necrotic Cell Death. J. EvidenceBased Complementary Altern. Med. 2011, 2011, 832805.

(56) Panhwar, Q. K.; Memon, S.; Bhanger, M. I. Synthesis, characterization, spectroscopic and antioxidation studies of $\mathrm{Cu}(\mathrm{II})-$ morin complex. J. Mol. Struct. 2010, 967, 47-53.

(57) Heim, K. E.; Tagliaferro, A. R.; Bobilya, D. J. Flavonoid antioxidants: chemistry, metabolism and structure-activity relationships. J. Nutr. Biochem. 2002, 13, 572-584.

(58) van Acker, S. A. B. E.; de Groot, M. J.; van den Berg, D.-J.; Tromp, M. N. J. L.; den Kelder, G. D.-O.; van der Vijgh, W. J. F.; Bast, A. A Quantum Chemical Explanation of the Antioxidant Activity of Flavonoids. Chem. Res. Toxicol. 1996, 9, 1305-1312.

(59) El-Neweshy, M. S.; El-Sayed, Y. S. Influence of vitamin C supplementation on lead-induced histopathological alterations in male rats. Exp. Toxicol. Pathol. 2011, 63, 221-227.

(60) Ledda-Columbano, G. M.; Columbano, A.; Pani, P. Lead and liver cell proliferation. Effect of repeated administrations. Am. J. Pathol. 1983, 113, 315-320.

(61) Adhikari, A.; Polley, N.; Darbar, S.; Bagchi, D.; Pal, S. K. Citrate functionalized $\mathrm{Mn} 3 \mathrm{O} 4$ in nanotherapy of hepatic fibrosis by oral administration. Future Sci. OA 2016, 2, FSO146.

(62) Adhikari, A.; Polley, N.; Darbar, S.; Pal, S. K. Therapeutic Potential of Surface Functionalized Mn3O4 Nanoparticles Against Chronic Liver Diseases in Murine Model. Mater. Focus 2017, 6, 280289.

(63) Polley, N.; Saha, S.; Adhikari, A.; Banerjee, S.; Darbar, S.; Das, S.; Pal, S. K. Safe and symptomatic medicinal use of surfacefunctionalized $\mathrm{Mn} 3 \mathrm{O} 4$ nanoparticles for hyperbilirubinemia treatment in mice. Nanomedicine 2015, 10, 2349-2363.

(64) El-Sayed, Y. S.; El-Neweshy, M. S. Impact of lead toxicity on male rat reproduction at "hormonal and histopathological levels". Toxicol. Environ. Chem. 2010, 92, 765-774.

(65) Buchheim, K.; Stoltenburg-Didinger, G.; Lilienthal, H.; Winneke, G. Myopathy: a possible effect of chronic low level lead exposure. NeuroToxicology 1998, 19, 539-545.

(66) Fonte, R.; Agosti, A.; Scafa, F.; Candura, S. M. Anaemia and abdominal pain due to occupational lead poisoning. Haematologica 2007, 92, e13-e14.

(67) Sarkar, P. K.; Halder, A.; Adhikari, A.; Polley, N.; Darbar, S.; Lemmens, P.; Pal, S. K. DNA-based fiber optic sensor for direct invivo measurement of oxidative stress. Sens. Actuators, B 2018, 255, 2194-2202. 